\title{
Salt crystallization in porous construction materials II. Mass transport and crystallization processes
}

\author{
V. López-Acevedo ${ }^{\mathrm{a}, *}$, C. Viedma ${ }^{\mathrm{a}}$, V. Gonzalez ${ }^{\mathrm{b}}$, A. La Iglesia ${ }^{\mathrm{c}}$
}

\begin{abstract}
In order to study the processes of salt weathering of monumental stones, several samples were partially immersed in sodium, potassium and magnesium sulphate solutions which ascended through their capillary network and, eventually, crystallized. This procedure pretends to simulate the conditions in which foundations and lower walls of building structures are, within the zone of capillary rise of saline groundwater. Mass transport and the rhythmic nature of crystallization fronts inside samples reminds the Liesegang phenomenon, so they have been considered as a form of dissipative structures. The saline deposits developed on the surface of the samples were efflorescences (mirabilite and epsomite), subefflorescences (picromerite, aphthitalite and arcanite) and crusts (aphthitalite and arcanite). The most devastating effects resulted from massive crystallization inside the samples or from surface peeling due to the development of subefflorescences or crusts.
\end{abstract}

Keywords: Salt weathering; Salt crystallization; Porous media; Dissipative structures

\section{Introduction}

Weathering in natural stones of monuments and buildings have been studied in the past by several authors. We can find detailed reviews [1] of past experiences on the subject of Preservation of Architectural Heritage. In his books on architecture, Vitrubio already refers to "the durability of materials". Afterwards, in the 14th century, Alberti suggested direct observation of stones in old buildings to determine "rock strength in the presence of dampness, frost and salts".

The 19th century brings about the first studies on conservation performance in various European buildings. However, it was not until the beginning of the 20th century that a really scientific and experimental approach to weathering and preservation of monumental stones is carried out [2]. At that time, an analytical methodology to study the weathering and durability of these building materials was proposed which has persisted until today [2-4]. In recent years, the scientific community has 
taken a great interest in this problem and has sought results from different points of view, as there are several reasons and processes resulting in stone decay in monuments [5-7].

One of the main reasons for weathering of building stones is crystallization of soluble salts. These are usually originated in the ground or in the mortar, but might also belong to the stone itself; they flow as a solution through a complex stone capillary system towards the stone's surface [5]. Under favourable conditions, these salts crystallize as efflorescences at the stone's surface, or subefflorescences if below it.

This mechanism, which might lead to the complete decay and destruction of the stone, is also influenced by the substrate's nature, climatic conditions, and salt-system characteristics [8]. Therefore, textural anisotropy, pores size and distribution within the building stone, relative humidity and temperature, and chemistry of the saline system solutions, will control the process which will take place.

Soluble-salt crystallization inside porous materials generates crystallization and/or hydration pressures likely to exceed the elastic limit of the material, causing its failure [5]. A theoretical method has been developed to determine crystallization pressures of gypsum inside a porous material, based in the characteristics of the porous system of the stone [9]. In a previous work [10], different porous materials were weathered experimentally by salt crystallization resulting from capillary ascension of some saline solutions. We calculated the crystallization pressures from the solubility of salts and compared them to their experimentally measured tensile strength. We inferred that it is possible to predict the behaviour of porous materials due to salt crystallization knowing pore volume, pore size distribution, tensile strength of these materials and the values of crystallization pressures of the different salts which appear.

The aim of this work is to study and discuss the above experimental crystallization process. In our experiences, we have attempted to reproduce the mechanisms involved in natural weathering of monumental stones by means of salts crystallization from solutions rising up through the capillary system from the substrate into the stone, following procedures modified from Sperling and Cooke [11].
Sodium, potassium, magnesium and sulphate ions were selected to prepare the experimental solutions, due to their systematic presence in the efflorescences of monumental stones [8], their generalized use as a standard method in the study of stone building decay [12], and the accumulation of data about their behaviour in aqueous solutions [13-15]. The results obtained represent an interesting contribution to the knowledge of some aspects of building materials weathering in natural environments.

\section{Experimental procedure}

The chemistry of salt solutions, the type of porous materials, the method used, the time and the conditions of salt supply to the samples, were described in a previous paper (part I of this study), Ref. [10].

The time and spatial evolution of the crystallization process could be observed on a few calcium carbonate agglomerate samples. Porosity and pore-size distribution is higher and far more uniform in these artificial samples than in the natural material [10], thus allowing the experimental data to be taken faster. This also permits to compare different results. Samples were partially immersed in a $0.5 \mathrm{M}$ solution of potassium dichromate, which produces easily recognizable orange-coloured crystals. After 24, 48 and $72 \mathrm{~h}$, samples were extracted from the solution, bound into epoxy, and then cut along the axis of the cylinders to enable observation of the resulting changes.

Building stone samples were also cut in a similar way at the end of the treatment periods so that changes could be observed.

Efflorescences, crusts and other forms of crystallization were studied using binocular lens. Some samples were also observed under scanning electron microscope (JEOL. JSM 6.400). Energy dispersive X-ray techniques were useful to obtain qualitative chemical microanalysis, and X-ray diffraction was employed for mineralogical identification. In order to avoid possible transformations within samples during drying, grinding and sieving, analyses were carried out without any previous treatment. 


\section{Results}

\subsection{Calcium carbonate agglomerate in} $\mathrm{Na}_{2} \mathrm{SO}_{4}-\mathrm{K}_{2} \mathrm{SO}_{4}-\mathrm{H}_{2} \mathrm{O}$ system

Results obtained from calcium carbonate agglomerate samples immersed in the $\mathrm{Na}_{2} \mathrm{SO}_{4}-\mathrm{K}_{2} \mathrm{SO}_{4}$ $\mathrm{H}_{2} \mathrm{O}$ solution system are summarized in Fig. 1.
The figure points out the rapid growth of mirabilite $\left(\mathrm{Na}_{2} \mathrm{SO}_{4} \cdot 10 \mathrm{H}_{2} \mathrm{O}\right)$ whiskers after about $24 \mathrm{~h}$, resulting in surface flaking on samples. This phenomenon is particularly outstanding in solutions with high $\mathrm{Na}_{2} \mathrm{SO}_{4}$ contents. Mirabilite crystals dehydrate, sometimes in a few hours, into thenardite $\left(\mathrm{Na}_{2} \mathrm{SO}_{4}\right)$ crystals, becoming a pulverulent efflorescences on the sample. Solutions with $\mathrm{K}_{2} \mathrm{SO}_{4}$
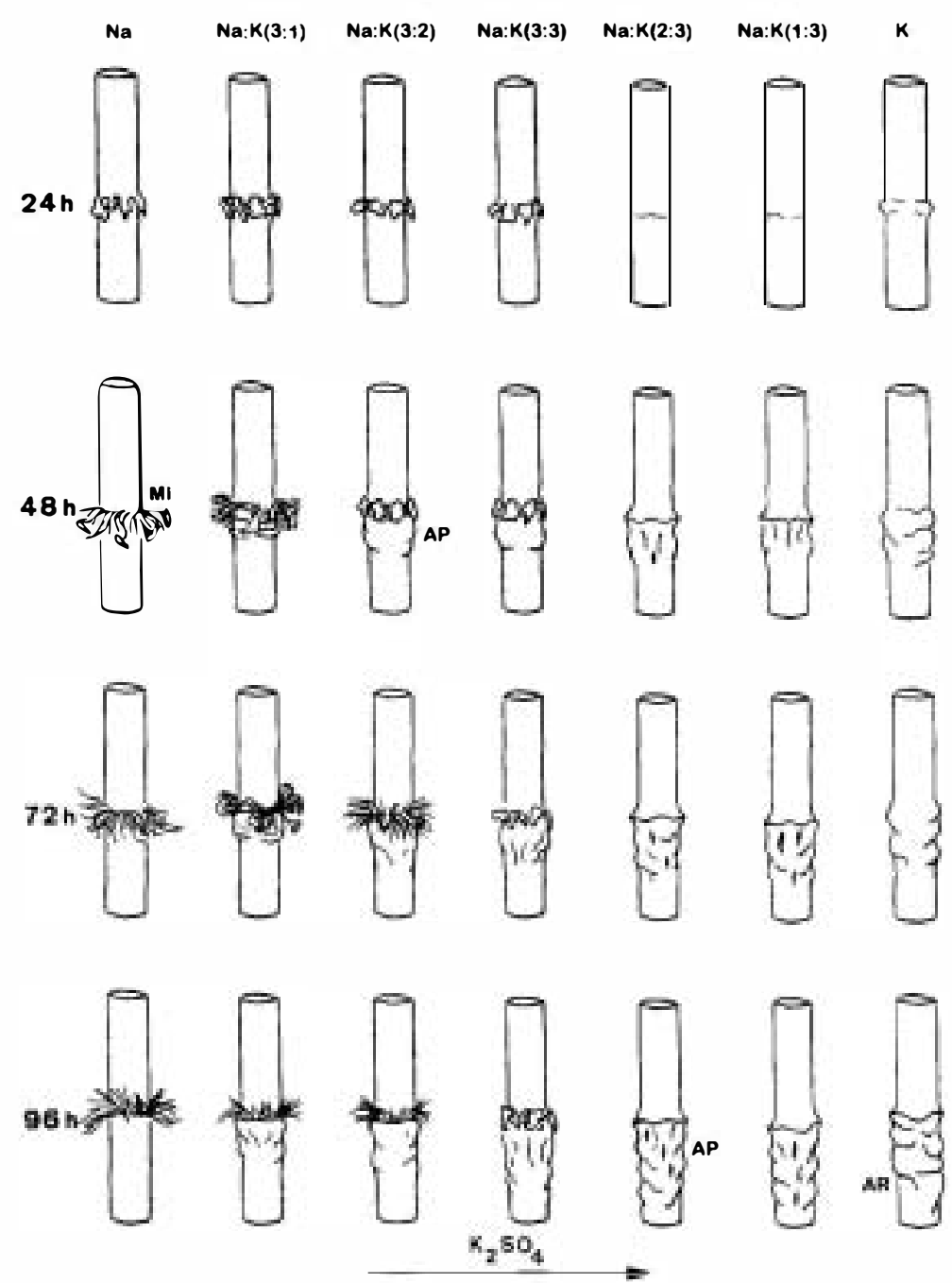

Fig. 1. Time development of the process in the carbonate agglomerate samples immersed in $\mathrm{Na}_{2} \mathrm{SO}_{4}-\mathrm{K}_{2} \mathrm{SO}_{4}-\mathrm{H}_{2} \mathrm{O}$ solutions: in experiments with $\mathrm{Na}_{2} \mathrm{SO}_{4} / \mathrm{K}_{2} \mathrm{SO}_{4}<1$ aphthitalite (AP) and/or arcanite (AR) crusts with small longitudinal crevices and a transversal crack are formed. In experiments with $\mathrm{Na}_{2} \mathrm{SO}_{4} / \mathrm{K}_{2} \mathrm{SO}_{4} \geqslant 1$ an aphthitalite crust and mirabilite (MI) whiskers, which push off the scales of agglomerate, are formed. In experiments with $\mathrm{Na}_{2} \mathrm{SO}_{4}$ alone, no crusts are formed. 


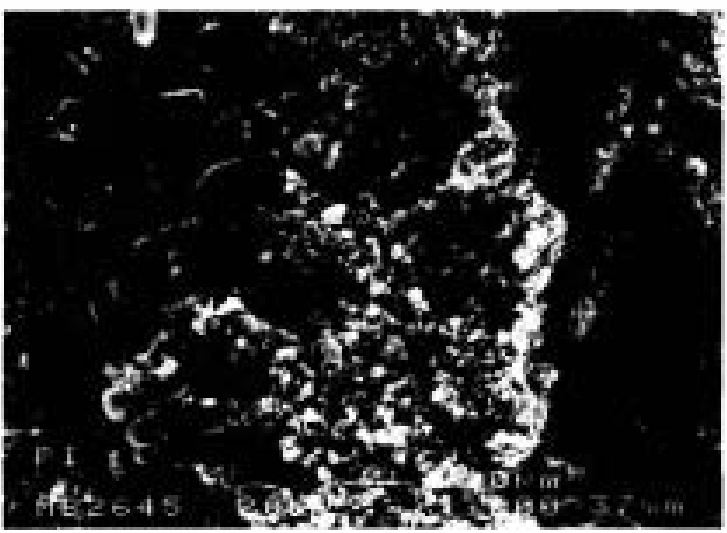

Fig. 2. SEM. X1000. Wrinkled crust from an agglomerate. $\mathrm{K}$ is present in the large isometric crystals (arcanite or aphthitalite), whereas $\mathrm{Ca}$ appears in the small calcite crystals.

contents produce wrinkled and frequently banded crusts. Aphthitalite $\left(\mathrm{K}_{3} \mathrm{Na}\left(\mathrm{SO}_{4}\right)_{2}\right)$ and/or arcanite $\left(\mathrm{K}_{2} \mathrm{SO}_{4}\right)$, together with calcite from the sample, were the crystalline phases identified (Fig. 2). These crusts are more significant in samples immersed in solutions with low $\mathrm{Na}_{2} \mathrm{SO}_{4} / \mathrm{K}_{2} \mathrm{SO}_{4}$ ratios. Formation of both whiskers and crusts occur some $2-4 \mathrm{~cm}$ above the free surface of the solution. This crystallization level is a function of temperature and relative humidity. The deposit of salt increases with time and the crust descends towards the solution. At this time the sample can break up along a parabolic crack which corresponds to the maximum level reached by the solution. An inner hard cluster of aphthitalite and arcanite crystals is formed into this parabolic crack.

\subsection{Calcium carbonate agglomerate in $\mathrm{MgSO}_{4}-\mathrm{K}_{2} \mathrm{SO}_{4}-\mathrm{H}_{2} \mathrm{O}$ system}

Experiments with $\mathrm{MgSO}_{4}-\mathrm{K}_{2} \mathrm{SO}_{4}-\mathrm{H}_{2} \mathrm{O}$ system (Fig. 3) show a similar behaviour, all samples formed of wrinkled crusts where arcanite and calcite were identified, except those samples immersed into $\mathrm{MgSO}_{4}$ solutions. These last crusts are forced out by acicular picromerite $\left(\mathrm{K}_{2} \mathrm{Mg}\left(\mathrm{SO}_{4}\right)_{2} \cdot 6 \mathrm{H}_{2} \mathrm{O}\right)$ or anhydrous potassium-magnesium sulphate $\left(\mathrm{K}_{2} \mathrm{Mg}\left(\mathrm{SO}_{4}\right)_{2}\right)$, growing under them and then progressively peeling them off. Such crystals grow at right angles to the crusts, in a sort of sandwich structure produced by the repetition of this process (crust-crystal formation) several times during the experiments (Fig. 4a and Fig. 4b). Epsomite $\left(\mathrm{MgSO}_{4} \cdot 7 \mathrm{H}_{2} \mathrm{O}\right)$ crystals are found, alone or together with picromerite, in experiments carried out with high $\mathrm{MgSO}_{4} / \mathrm{K}_{2} \mathrm{SO}_{4}$ ratio solutions. Sometimes, epsomite crystals can be dehydrated into hexahydrite $\left(\mathrm{MgSO}_{4} \cdot 6 \mathrm{H}_{2} \mathrm{O}\right)$.

\subsection{Calcium carbonate agglomerate in dichromate solution}

Results obtained from calcium carbonate agglomerate samples in dichromate solution can be seen in Fig. 5, which shows the progression of the coloured solution, as well as the eventual crystallization of $\mathrm{K}_{2} \mathrm{Cr}_{2} \mathrm{O}_{7}$ after three days. There are some aspects to be pointed out: the sample immersed for $24 \mathrm{~h}$ showed the advance of the solution along the sample in a parabolic front which is followed by a band with isolated dichromate crystals. The sample immersed for $48 \mathrm{~h}$ showed a second crystalline parabolic front, some $2-4 \mathrm{~mm}$ away from the first one. At the end of the experiment, after $72 \mathrm{~h}$, two bands of small crystals between three parabolic boundaries could be easily distinguished. The high concentration of small crystals in the upper band produced the disruption of the sample just where the third boundary was.

\subsection{Rock samples}

From rock samples experiments the following can be pointed out: both the physical properties of the samples (porosity, texture, cracks and irregularities) and the nature and concentration of the solutions are decisive factors in the results obtained from building stone samples.

None of the studied samples from Colmenar showed any weathering, cracks or fracture zones resulting from the crystallization process. Only surfacial efflorescences appeared at their surfaces. Their composition depended on the nature of the solutions in which the samples were immersed: mirabilite whiskers which eventually became dusty thenardite crusts over samples treated with $\mathrm{Na}_{2} \mathrm{SO}_{4}-\mathrm{K}_{2} \mathrm{SO}_{4}$ solutions and acicular epsomite and picromerite crystals over samples treated with 

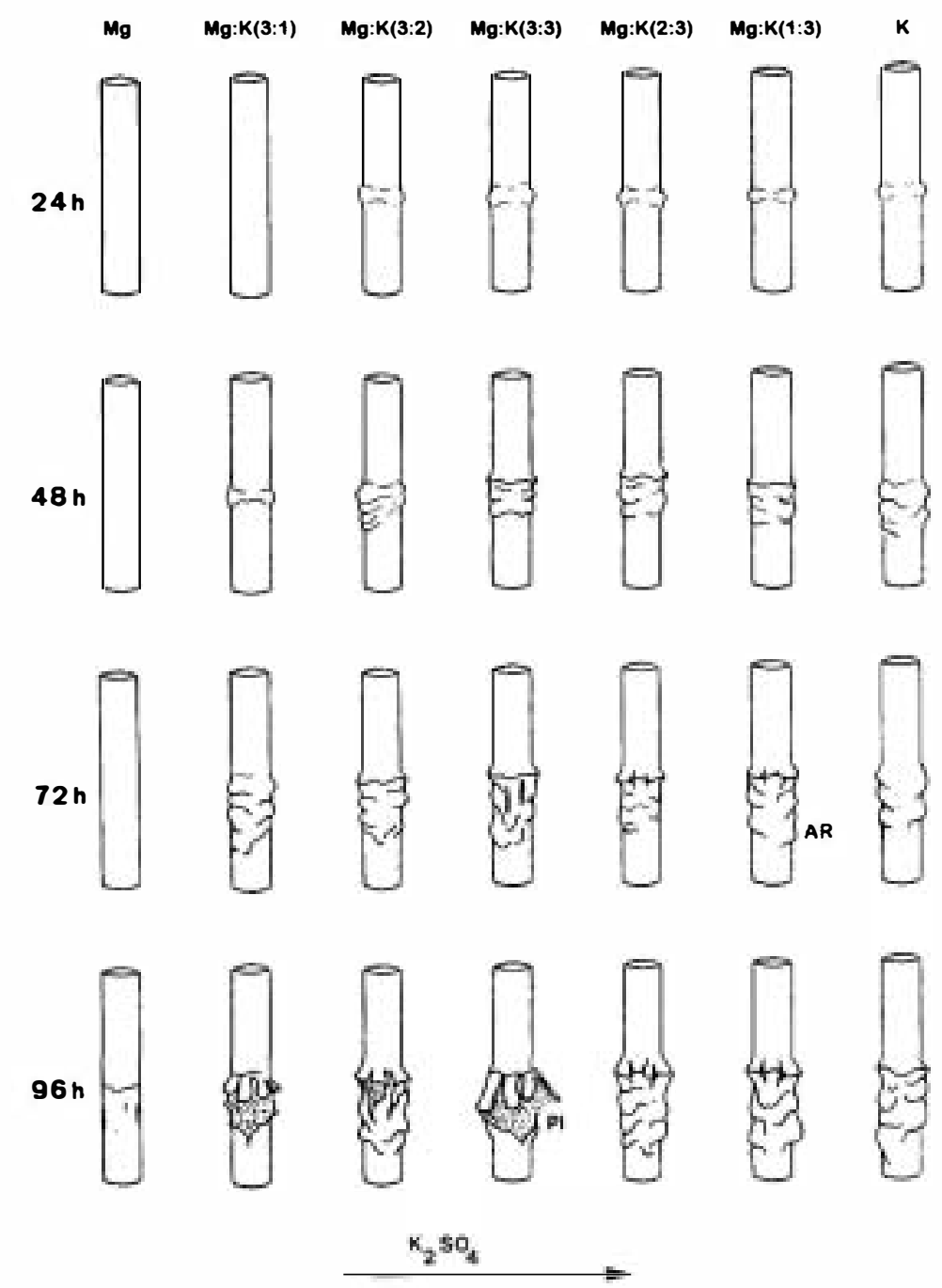

Fig. 3. Time development of the process in the carbonate agglomerate samples immersed in $\mathrm{MgSO}_{4}-\mathrm{K}_{2} \mathrm{SO}_{4}-\mathrm{H}_{2} \mathrm{O}$ solutions: In experiments with $\mathrm{Mg}_{2} \mathrm{SO}_{4} / \mathrm{K}_{2} \mathrm{SO}_{4}<1$ arcanite crusts with small longitudinal crevices and a transversal crack are formed. In experiments with $\mathrm{MgSO}_{4} / \mathrm{K}_{2} \mathrm{SO}_{4} \geqslant 1$ the longitudinal cracks widen up and lift the arcanite crusts, forced out by acicular picromerite (PI) crystals.

$\mathrm{MgSO}_{4}-\mathrm{K}_{2} \mathrm{SO}_{4}$ solutions. However, samples coming from Cerro de la Rosa showed the first crystallization processes related to cracks and irregularities. The extension of saline supply led to flake off in nonexcessively polished surfaces and, eventually, to the disruption of the sample. Longitudinal cutting revealed a similar parabolic pattern to that observed in agglomerate samples (Fig. 6) in the cracking zone.
It was apparent from samples partially immersed in each of the pure saline solutions, that cracking affected primarily and more efficiently to those samples exposed to the highest concentrations, and that $\mathrm{Na}_{2} \mathrm{SO}_{4}$ and $\mathrm{MgSO}_{4}$ solutions tend to produce whiskers and efflorescences at the surface of the samples, whereas $\mathrm{K}_{2} \mathrm{SO}_{4}$ solutions preferably produced subefflorescences under the surfaces, peeling them off (Fig. 7). 

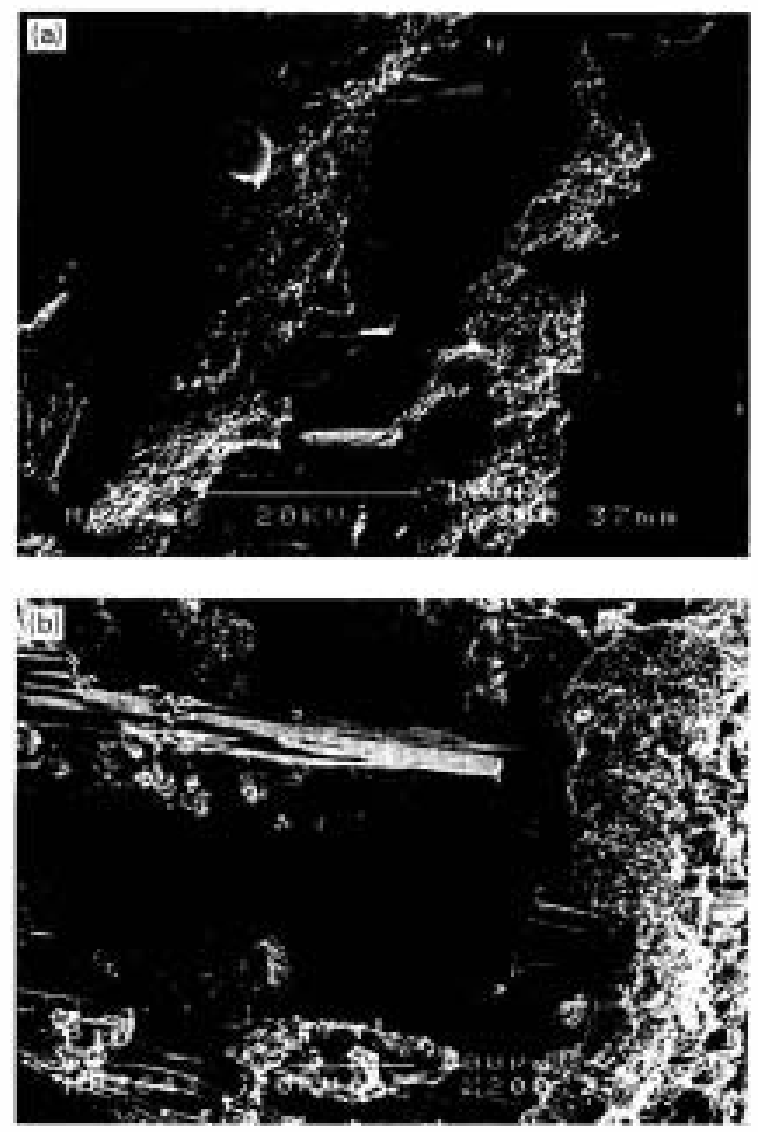

Fig. 4. (a) SEM. X350. Picromerite whiskers perpendicularly interlayers between two arcanite and calcite crusts. (b) SEM. X200. Picromerite whiskers showing inner channels.

\section{Discussion}

\subsection{Processes inside porous materials}

Two remarkable aspects in the processes observed inside the agglomerates and building stones samples are the rhythmic arrangement of crystallization fronts and their parabolic shape (Figs. 5 and 6). Such banded structures could be related with dissipative structures, resembling Liesegang's rings, which reflect the fluctuations in a system far from equilibrium. When nucleation and transportation through porous materials occur, as is the case, structures of this kind can be expected, since these materials enable the system to go beyond the equilibrium and the processes to be nonlinear [16].

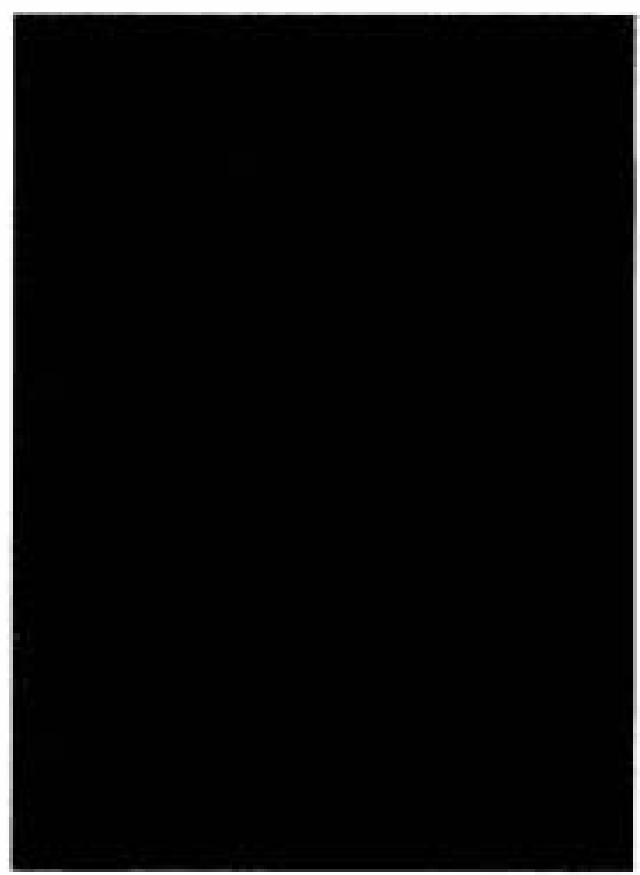

Fig. 5. Potassium dichromate crystal fronts inside the two agglomerate samples $(80 \times 10 \mathrm{~mm}$ cylinder $)$. The parabolic shape, the rhythmic structure and the cracking are recognizable.

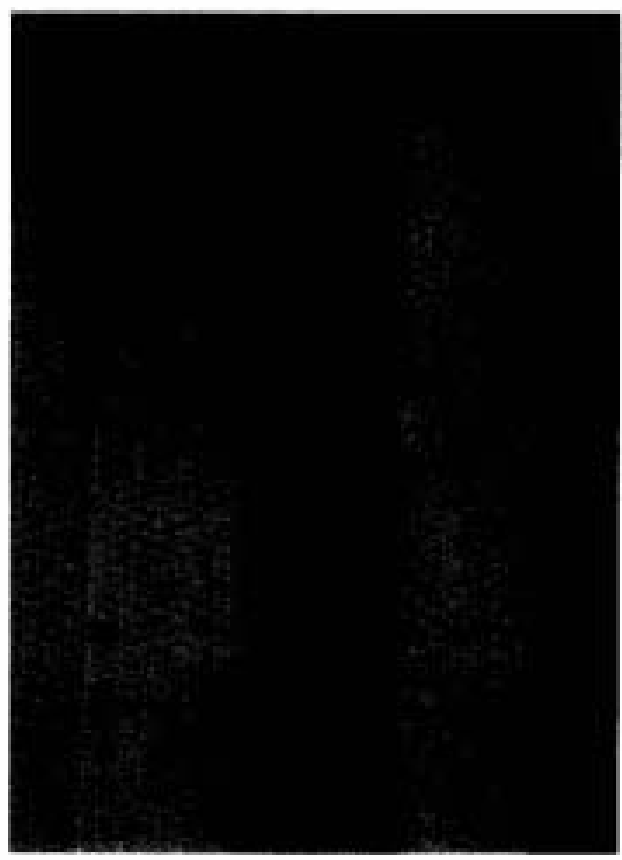

Fig. 6. Parabolic fronts in a building stone sample (left) and in an agglomerate sample (right) $(120 \times 15 \times 15 \mathrm{~mm}$ prism and $80 \times 10 \mathrm{~mm}$ cylinder $)$. 


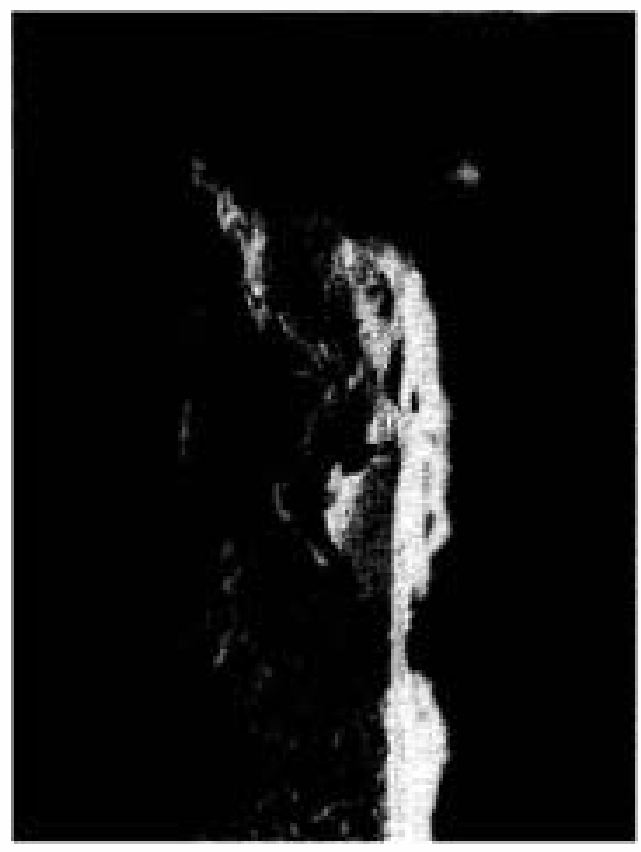

Fig. 7. $\mathrm{K}_{2} \mathrm{SO}_{4}$ subefflorescences $(\mathrm{Na}: \mathrm{K} \quad(1: 3)),(120 \times 15 \times$ $15 \mathrm{~mm}$ prism).

As long as the mechanism in the generation of dissipative structures is Oswald's supersaturationnucleation-depletion cycle, the presence of banded zones in our experimental system is totally justified by the following sequence:

- Concentration in the solutions increases with evaporation, as it flows upwards through the capillary network in the sample, until the equilibrium concentration is reached.

- A progressive increase of supersaturation takes the system far enough from the equilibrium to reach the unstable region, where generalized nucleation results at the first crystallization front.

- The crystals exert a drain effect and the system tends to be locally depleted in ions, avoiding the crystallization around it.

- When supersaturation reaches a level beyond the nucleation threshold, far enough from the first band so as not to disturb the drain effect, the process described above is repeated and a second front of crystallization can begin.

- This process will continue until the consumption of the solution or the disruption of the diffusion column, as it happens in our experiments when the crystallization pressure surpasses the tensile strength of the samples [10].

The parabolic shape of the fronts observed throughout all the process can be explained as the result of the concentration gradient produced by the more efficient evaporation of the solvent on the surface of the samples than inside them. This makes the solution to flow better in the centre than in the periphery. This also explains the same parabolic arrangement of the crystalline fronts, revealing the surfaces of equal concentration through the samples. However, textural anisotropy of building stone samples leads to singular behaviours in the crystallization processes, making it sometimes difficult comparing them. The first crystals in building stone samples grow inside cracks or irregular areas at random.

\subsection{Processes on the surface of porous materials}

Three kinds of saline deposits resulted from the experiments, i.e. efflorescences, subefflorescences and crusts, differing in chemical composition, morphology of crystalline phases and the particularities of the resulting weathering processes.

The way in which crusts and subefflorescences are formed is similar to that discussed by Winkler [5], and according to a model of Schmidt [17]: the saline solution moves towards the surface of the samples, thus becoming supersaturated, and nucleation begins without reaching the surface itself. The first salts, crystallized are aphthitalite and/or arcanite. These crystals are very isometric, and they produce cementation of the superficial particles of the samples (Fig. 2), thus appearing a thin, indurated crust. Later, the crust loses its support and starts peeling off, since salts start to crystallize underneath (Fig. 7). If the crystals in this second generation are also isometric the outer crusts wrinkle and warp (Figs. 1 and 3). When the crystals formed at this stage are highly anisotropic in their morphology, such as the picromerite whiskers shown in Fig. 4a and Fig. 4b, the crusts are detached by their growth and they can eventually fall off (Fig. 3). After this peeling, the surface of the sample is ready for the formation of another crust as the process is repeated. Fig. $4 \mathrm{a}$ and Fig. $4 \mathrm{~b}$ show picromerite whiskers pushing off the 
first crust while they make up a second and deeper crust.

Nucleation and subsequent growth of epsomite or mirabilite whiskers take place in the surface of the samples, where the supersaturation rate is higher in our system, in contrast to the inner parabolic front, where isometric crystals of arcanite and aphthitalite are formed. The growing whiskers through the pores are pushed out in response to the crystallization pressure [18].

\section{Conclusions}

Several stages can be distinguished in the weathering of these materials: rise of the saline solution through the material, ion-enrichment in the solution due to evaporation and consequently, salt crystallization.

The agglomerate samples yielded important information about the processes occurring inside the samples and behave as an excellent demonstration of the salt weathering processes of building stones in natural environments.

The deposit of salt appears in distinct parabolic fronts resembling Liesegang's rings which can lead to the disruption of the sample when the crystallization pressure surpasses the tensile strength of these materials.

The process depends basically on the textural and surface characteristics of the samples. The kind of weathering varies with the crystals morphology, related with the supersaturation rate, and the chemical composition of the saline solution. Efflorescences appear when it is rich in sodium or magnesium sulphate, whereas subefflorescences and crusts arise from potassium sulphate-rich solutions. The concentration of salts directly determines the degree of weathering produced in the materials.

\section{Acknowledgements}

The authors wish to thank the Comunidad Autónoma of Madrid for the financial support of this paper (00061/94 and 0126/94 Projects) and Dr. Juan Luis Martin-Vivaldi for his precious assistance.

\section{References}

[1] E.M. Sebastian, C.M. Rodriguez-Navarro, MOPU Ingenieria Civil 96 (1995) 167.

[2] R.J. Schaffer, DSIR, Building Research Special Report No 18, Stationary Office, London, 1932, p. 34.

[3] S.A. Russell, Stone preservation commitee report (Appendix I), H.M. Stationary Office, London, 1927.

[4] D.B. Honeyborne, P.B. Harris, in: Proc. 10th Symp. Colston Res. Soc., The Structure and Properties of Porous Materials, Butterworths, London, 1958, p. 343.

[5] E.M. Winkler, Stone: Properties, Durability in Man's Environment, Springer, New York, 1975, p. 230.

[6] I.S. Evans, Rev. Geomor. Dyn. 19 (1970) 155.

[7] C. Sainz-Gimenez, in: Proc. Int. Symp. on the Oxalate Films: Origin and Significance in the Conservation of Work of Art, Milano, 1989, p. 207.

[8] A. Arnold, K. Zehnder, in: Proc. 1st Int. Symp. on Bari: the Conservation of Monuments in the Mediterranean Basin. 1989, p. 31.

[9] R. Rossi-Manaresi, A. Tucci, in: Proc. 1st Int. Symp. on Bari: the Conservation of Monuments in the Mediterranean Basin, 1989, p. 97.

[10] A. La Iglesia, V. Gonzalez, V. López-Acevedo, C. Viedma, J. Crystal Growth 177 (1997) 111.

[11] C.H.B. Sperling, R.U. Cooke, Earth Surface Processes and Landforms 70 (1985) 541.

[12] Standard Test Method for Soundness of Aggregates by Use of Sodium Sulphate and Magnesium Sulphate. Annual Book of ASTM Standards, vol. 04.02, ASTM C 88, American Society for Testing Materials, New York, 1990.

[13] J.L. Martin-Vivaldi Caballero, Estudio del efecto de colorantes orgánicos sobre el hábito de crecimiento de compuestos iónicos (Fuchina ácida-sulfato potásico), $\mathrm{PhD}$ Thesis, Ed. Univ. Compl. de Madrid, 1983, p. 155.

[14] L. Fernandez Diaz, M. Prieto, Materiales y Procesos Geológicos, vol. V, 1987, 207.

[15] D.J. McMahon, P. Sandberg, K. Folliard, P.K. Mehta, in: Proc. 7th Int. Cong. on Deterioration and Conservation of Stone, vol. 1, 1992, p. 705.

[16] P.J. Ortoleva, Geochemical Self-Organization, Oxford University Press, New York, 1994, p. 411.

[17] K. Schmidt-Thomsen, Deutsche Kunts und Denkmalpflege (1969) 11.

[18] E.I. Givargizov, Highly Anisotropic Crystals, Terra Scientific Publishing Company, Tokyo, 1987, p. 394. 